\title{
Los depósitos clásticos pos-Laramide de la Sierra de Guanajuato: Implicaciones de su composición en la evolución tectono-sedimentaria y paleogeográfica
}

\author{
The post-Laramide clastic deposits of the Sierra \\ de Guanajuato: Compositional implications on the \\ tectono-sedimentary and paleographic evolution
}

\author{
R. Miranda-Avilés ${ }^{1}$, M.J. Puy-Alquiza ${ }^{1}$, L. Omaña ${ }^{2}$, I. Loza-Aguirre ${ }^{1}$ \\ 1 Universidad de Guanajuato, Departamento de Minas Metalurgia y Geología, Ex-Hacienda San Matías, C.P. 36020, \\ Guanajuato, Gto., México. Email: rmiranda@ugto.mx \\ 2 Instituto de Geología, Universidad Nacional Autónoma de México, Ciudad Universitaria, Delegación Coyoacán, 04510, \\ México, D.F., México.
}

\section{RESUMEN}

Este artículo presenta los resultados del estudio sobre la sedimentación, los ambientes sedimentarios, la evolución tectono-sedimentaria y paleogeográfica de los depósitos clásticos pos-Laramide y pre-vulcanismo de la Sierra Madre Occidental en la Sierra de Guanajuato. Los depósitos clásticos rojos analizados corresponden al Conglomerado Guanajuato y al Conglomerado Duarte del Eoceno que fueron depositados en la parte media y distal de abanicos aluviales. Los depósitos estudiados están constituidos de clastos de calizas, granito, andesita, rocas sedimentarias, diorita y piroxenita, que indican la erosión de bloques levantados del complejo basal de la Sierra de Guanajuato (Terreno Guerrero). El análisis composicional y petrográfico de clastos de calizas permitió reconocer calizas de cuenca y calizas de plataforma somera provenientes del complejo basal de la Sierra de Guanajuato (Cuenca Arperos). Las calizas de plataforma somera presentan fragmentos esqueletales de bivalvos, braquiópodos, gasterópodos, equinodermos y foraminíferos bentónicos del Berriasiano-Valanginiano. Los clastos de caliza de plataforma se interpreta que podrían proceder de facies someras limítrofes de la cuenca Arperos, cuyos afloramientos originales actualmente no afloran en la Sierra de Guanajuato.

Palabras clave: Capas rojas Mesa Central; Conglomerado Guanajuato; Conglomerado Duarte; Cuenca Arperos; calizas Berriasiano-Valanginiano.

\section{ABSTRACT}

This article presents the results of the study on sedimentation, sedimentary environments, tectono-sedimentary and paleogeographic evolution of post-Laramide clastic deposits and pre-volcanism of the Sierra Madre Occidental in the Sierra de Guanajuato, central Mexico.

The Eocene Duarte Conglomerate and Guanajuato Conglomerate were deposited in the middle and distal parts of alluvial fans. The studied rocks are composed of limestone clasts, granite, andesite, metasediments, diorite, and pyroxenite, indicating the erosion of uplifted blocks of the basal complex of the Sierra de Guanajuato (Arperos basin). The petrographic and compositional analysis of limestone shows a textural variation from basin limestones

Recibido el 20 de abril de 2016 / Aceptado el 26 de septiembre de 2016 / Publicado online el 24 de noviembre de 2016

Citation / Cómo citar este artículo: Miranda-Avilés, R. et al., (2016). Los depósitos clásticos pos-Laramide de la Sierra de Guanajuato: Implicaciones de su composición en la evolución tectono-sedimentaria y paleogeográfica. Estudios Geológicos 72(2): e058. http://dx.doi.org/10.3989/egeol.42480.417.

Copyright: (c) 2016 CSIC. This is an open-access article distributed under the terms of the Creative Commons Attribution-Non Commercial (by-nc) Spain 3.0 License. 
and shallow platform limestones. The shallow platform limestone contain bivalves, brachiopods, gastropods, echinoderms and benthic foraminifera from the Berriasian-Valanginian. The shallow-water limestone corresponds to the boundary of the Arperos basin whose original outcrops currently not outcrop in the Sierra de Guanajuato.

Keywords: Mesa Central; red beds; Guanajuato Conglomerate; Duarte Conglomerate; Arperos basin; Berriasian-Valanginian limestone.

\section{Introducción}

En el centro y sur de México afloran capas rojas del Eoceno que sobreyacen discordantemente a rocas plegadas del Mesozoico y subyacen a rocas volcánicas félsicas del Eoceno y Oligoceno (Edwards, 1955; Aranda-Gómez y McDowell, 1998). Ejemplo de dichas capas rojas son el Conglomerado Guanajuato (CG) (Botsford, 1909; Edwards, 1955; Aranda-Gómez y McDowell, 1998) y el Conglomerado Duarte (CD) (MartínezReyes, 1992) en la Sierra de Guanajuato; la Formación Cenicera (Labarthe-Hernández et al., 1982) en el Estado de San Luis Potosí y las Capas Rojas de Pinos así como el conglomerado rojo de Zacatecas los cuales afloran en el estado de Zacatecas (Botsford, 1909; Edwards, 1955; Aranda-Gómez et al., 2007; Escalona-Alcázar et al., 2016) (Fig. 1).

Estas capas rojas fueron depositadas posteriormente a la deformación contráctil laramídica del Cretácico Superior-Eoceno Inferior (NietoSamaniego et al., 2005) por lo que han sido interpretadas como molasas acumuladas en bajos topográficos asociados al fallamiento que determinó el colapso del edificio orogénico (ArandaGómez y McDowell, 1998).

El presente trabajo se enfoca en el estudio sedimentológico y composicional del CD y CG de la Sierra de Guanajuato (Figs. 1 y 2). Se analiza la evolución de la sedimentación de los depósitos pos-Laramide en el límite sureste y suroeste de la Sierra de Guanajuato, utilizando el análisis de facies y la interpretación de ambiente sedimentario, así como la determinación de dirección de paleocorriente y la composición de las rocas clásticas. Los nuevos datos sedimentológicos y composicionales aportan información para reconstruir la historia de levantamiento y erosión pre- y pos-laramide de la Sierra de Guanajuato.

\section{Marco geológico de la Sierra de Guanajuato}

La Sierra de Guanajuato se localiza a lo largo del límite sur de la Mesa Central y forma parte del Terreno Compuesto Guerrero
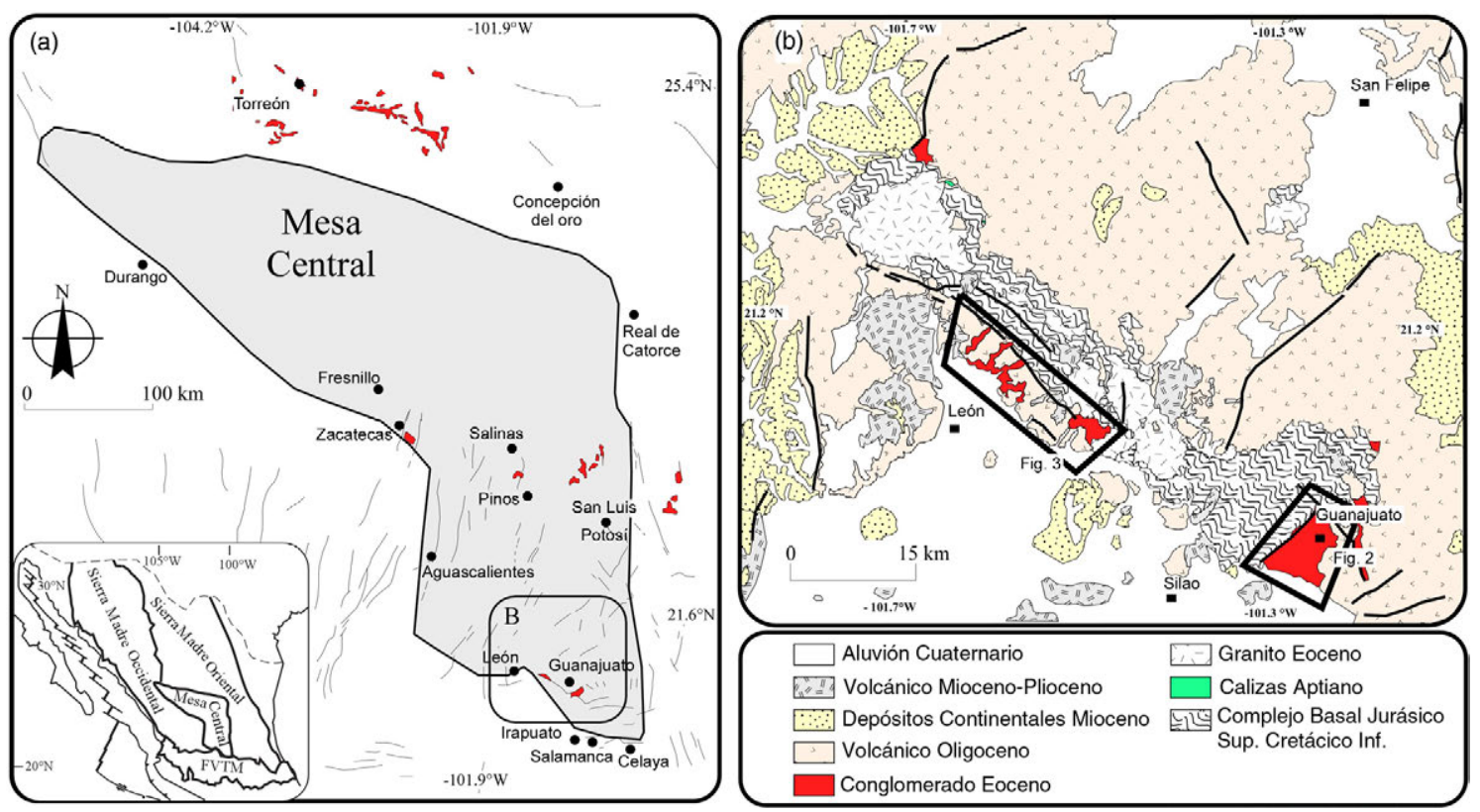

Fig. 1.-Localización y geología regional del área de estudio. 
(Centeno-García et al., 2008). Las rocas de la Sierra de Guanajuato han sido divididas en dos grupos litológicos de acuerdo con Aranda-Gómez et al. (2003): (1) El complejo basal del Jurásico Superior-Cretácico Inferior y (2) la cubierta vulcanosedimentaria del Cenozoico. Martini et al. (2011, 2013) dividen al complejo basal de la Sierra de Guanajuato en 2 conjuntos petrotectónicos. Un conjunto de arco denominado "Arco el Paxtle" emplazado tectónicamente arriba de un conjunto petrotectónico de cuenca de trasarco denominado "Cuenca Arperos". El Arco el Paxtle está conformado por el complejo intrusivo Tuna Manza y la Formación El Paxtle. El complejo intrusivo Tuna Manza se compone de gabro, diorita y tonalita (Lapierre et al., 1992; Ortíz-Hernández et al., 1992). La Formación El Paxtle está constituida de lavas basálticas almohadilladas, hialoclastitas, y tobas intercaladas con rocas volcanoclásticas y radiolaritas (Martini et al., 2011).

La Cuenca Arperos en la Sierra de Guanajuato presenta una proveniencia asimétrica de sus sedimentos (Martini et al., 2011, 2013). La porción este de la cuenca recibió sedimentos del macizo continental Mexicano y está compuesta de alternancias de areniscas finas, capas delgadas de limolitas, lutitas y flujos riolíticos de la Formación Esperanza del Titoniano, que subyacen a lutitas y calizas del Cretácico Inferior de la Formación Valenciana (Martini et al., 2011). Por otra parte el oeste de la cuenca está constituida por las formaciones Cuestecitas y Arperos que están compuestas de lavas basálticas almohadilladas, radiolarita y turbiditas volcaniclásticas recicladas del conjunto El Paxtle.

Las rocas de la Cuenca Arperos y el conjunto de arco El Paxtle se encuentran plegadas afectadas por un bajo grado de metamorfismo y subyacen discordantemente a la caliza La Perlita del Albiano (Chiodi et al., 1988; Quintero-Legorreta 1992). Las rocas de la Sierra de Guanajuato fueron afectadas por 3 eventos contráctiles pre-Albianos (Martini et al., 2013) y un cuarto evento compresivo posterior al depósito de la Caliza La Perlita.

Durante el Paleógeno las rocas de la Sierra de Guanajuato fueron intrusionadas por el Granito Comanja, para el cual se ha obtenido una edad K-Ar en feldespato de 51+/-1.3 Ma (Stein et al., 1993) y una edad U-Pb en circón de 51.7+/-1.0 Ma (Botero Santa et al., 2015).

\section{Rocas volcánicas y sedimentarias del Cenozoico}

El complejo basal del Jurásico Superior-Cretácico Inferior de la Sierra de Guanajuato, está limitado en su parte superior por una discordancia angular y erosional que se extiende en toda la Mesa Central y que abarca un intervalo que va del Cretácico Superior al Paleoceno (Nieto-Samaniego et al., 2005). Esta discordancia subyace a capas rojas continentales del Eoceno (Aranda-Gómez y McDowell, 1998), entre las cuales se encuentran el CG y el CD que afloran principalmente en el borde oeste y suroeste de la Sierra de Guanajuato y son objeto del presente trabajo (Fig. 1).

El CG aflora en la Sierra de Guanajuato y ha sido descrito y cartografiado por Wandke y Martínez (1928); Guiza et al. (1949); Edwards (1955); Martínez-Reyes (1992) y Nieto-Samaniego (1992). La edad del CG fue determinada por medio de información paleontológica y radiométrica. Fries et al. (1955) analizaron restos de vertebrados colectados en el miembro inferior, 2 kilómetros al sur del poblado Marfil (Fig. 2). La información aportada por Fries et al. (1955) es poco precisa ya que la fauna Cenozoica colectada solo permitió inferir una edad no más joven que el Oligoceno temprano. Por otra parte Ferrusquia-Villafranca (1987), con base en restos de mamíferos (Viverravus sp. y Apheliscus), ubicó el miembro inferior entre el Eoceno medio (Luteciense) y el Eoceno tardío (Priaboniense). Sucesivamente, Aranda-Gómez y McDowell (1998) dataron isotópicamente una colada de basalto localizada muy próxima a la base del miembro inferior, con una edad K-Ar en roca entera de 49.3 +/-1.0 Ma. La edad para el miembro superior se estima anterior a $33.53+/-0.48 \mathrm{Ma}$ (Nieto-Samaniego et al., 2015), con base en el fechamiento de la cubierta volcánica. Recientemente Omaña et al., (2015) analizaron clastos de caliza del miembro inferior, reportando foraminíferos del Berriasiano-Valanginiano. El CD fue descrito originalmente por Martínez-Reyes (1992) en el borde WSW de la Sierra de Guanajuato. En el presente trabajo estudiamos siete localidades del municipio de León: Arroyo San Juan de Otates, El 


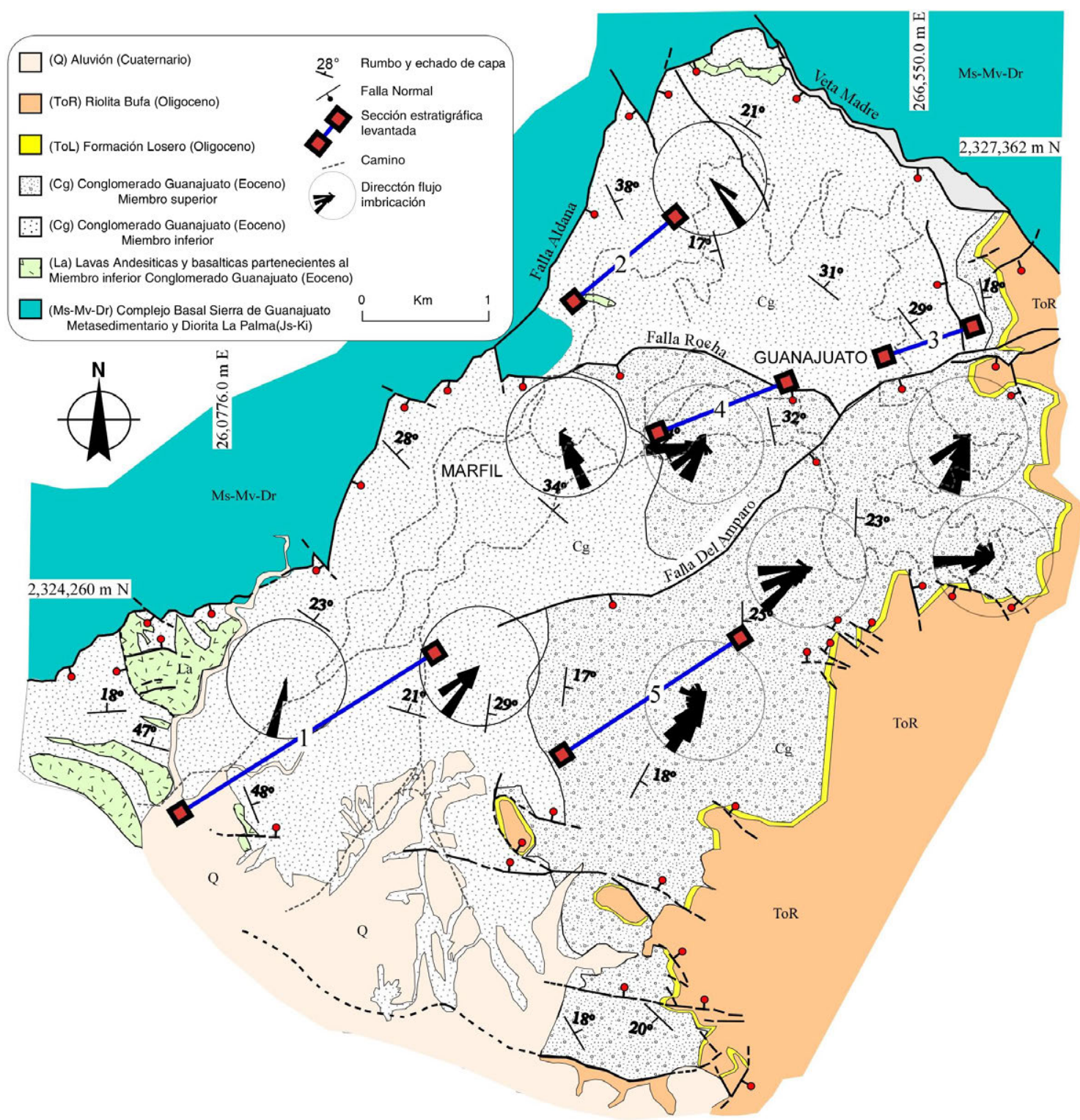

Fig. 2.-Carta geológica de afloramientos del Conglomerado Guanajuato. Las rosas corresponden a la dirección de flujo obtenida por imbricación de conglomerados.

Juache, La Laborcita, Arroyo Mastranto, Arroyo El Salto, Ibarrilla y Arroyo Grande (Fig. 3). El análisis sedimentológico y estratigráfico del CD se realizó con base en el análisis de litofacies utilizando la nomenclatura de facies fluvial propuesta por Miall (1996). El espesor máximo medido para esta unidad es de $1700 \mathrm{~m}$ en Arroyo Grande dividiéndolo en miembro inferior y superior. La edad del CD es considerada entre el Ypresiense (Eoceno temprano) y el Rupeliense (Oligoceno temprano), tomando en cuenta que Ruiz-González (2015) reportó una ignimbrita en la base del $\mathrm{CD}$, la cual fechó por $\mathrm{U}-\mathrm{Pb}$ en $48.8 \mathrm{Ma}$, mientras que el límite superior subyace a la Riolita Cuatralba del Rupeliense $(31.11 \pm 0.42$ Ma; Botero-Santa et al., 2015).

Las rocas volcánicas del Oligoceno sobreyacen a las capas rojas continentales del Eoceno y al complejo basal Mesozoico de la Sierra de Guanajuato, y tienen un rango de edad K-Ar comprendido entre 33 y 29 Ma (Nieto-Samaniego et al., 1996).

El patrón principal de fallamiento Cenozoico sigue un rumbo NW-SEy ha sido atribuido a diversos eventos 


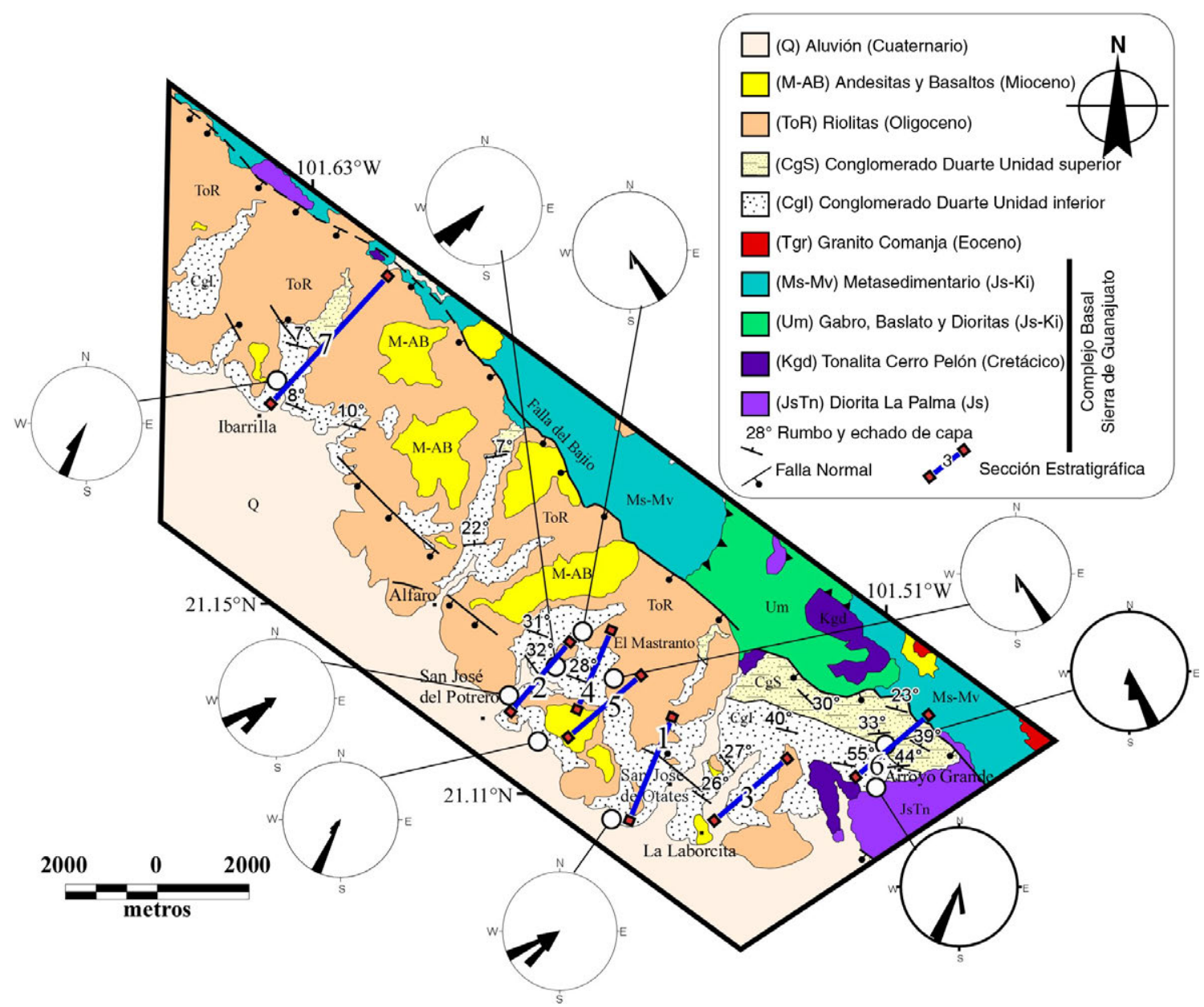

Fig. 3.-Carta geológica de afloramientos del Conglomerado Duarte. Las rosas corresponden a la dirección de flujo obtenida por imbricación de conglomerados.

de deformación (Aranda-Gómez y McDowell, 1998; Nieto-Samaniego, 1992). El extremo oeste y suroeste de la Sierra de Guanajuato está limitado por la falla del Bajío que representa una estructura con cinemática tipo normal (Nieto-Samaniego, 1992; QuinteroLegorreta, 1992) y una orientación de $\mathrm{N} 45^{\circ} \mathrm{W}$ con inclinación hacia el suroeste.

\section{Metodología}

El CG y CD fueron estudiados por medio de los datos sedimentológicos y estratigráfi$\cos$ de doce secciones estratigráficas medidas (Figs. 2, 3, 4 y 5). El análisis de facies consistió en definir litofacies utilizando la nomenclatura de facies fluvial propuesta por Miall (1996). Se midieron las direcciones de paleocorrientes a partir de estructuras de imbricación de clastos imbricados en los conglomerados y cada medición fue corregida a la horizontal de acuerdo a la metodología propuesta por Rust (1972). Los resultados fueron finalmente graficados en diagramas de roseta. Se realizó el conteo de composición de clastos de acuerdo a la metodología propuesta por Dürr (1994), usando 25 clastos por estación y separándolos cualitativamente en seis categorías, tales como caliza, granito, andesita, rocas metasedimentarias, diorita y piroxenita.

\section{Resultados}

\section{Conglomerado Guanajuato (CG)}

El CG tiene un espesor de entre 1500 a 2000 $m$ y fue dividido por Edwards (1955) en miembro inferior y miembro superior. Estratigráficamente 
sobreyace al complejo basal de la Sierra de Guanajuato y subyace a la cubierta volcánica cenozoica. El contacto con el complejo basal es por falla (Edwards, 1955) y solo en algunas localidades es posible observarlo como discordancia angular (Fig. 2; ej. al W de Guanajuato; $101.272^{\circ} \mathrm{W}$ y $\left.21.017^{\circ} \mathrm{N}\right)$. Las capas del CG se encuentran basculadas debido a fallamiento distensivo pos-Laramide que inició desde el Eoceno hasta el Oligoceno (Aranda-Gómez y McDowell, 1998).

El análisis sedimentológico y estratigráfico del CG se realizó con base en el análisis de litofacies de cinco secciones estratigráficas medidas en los alrededores de la ciudad de Guanajuato (Fig. 2).
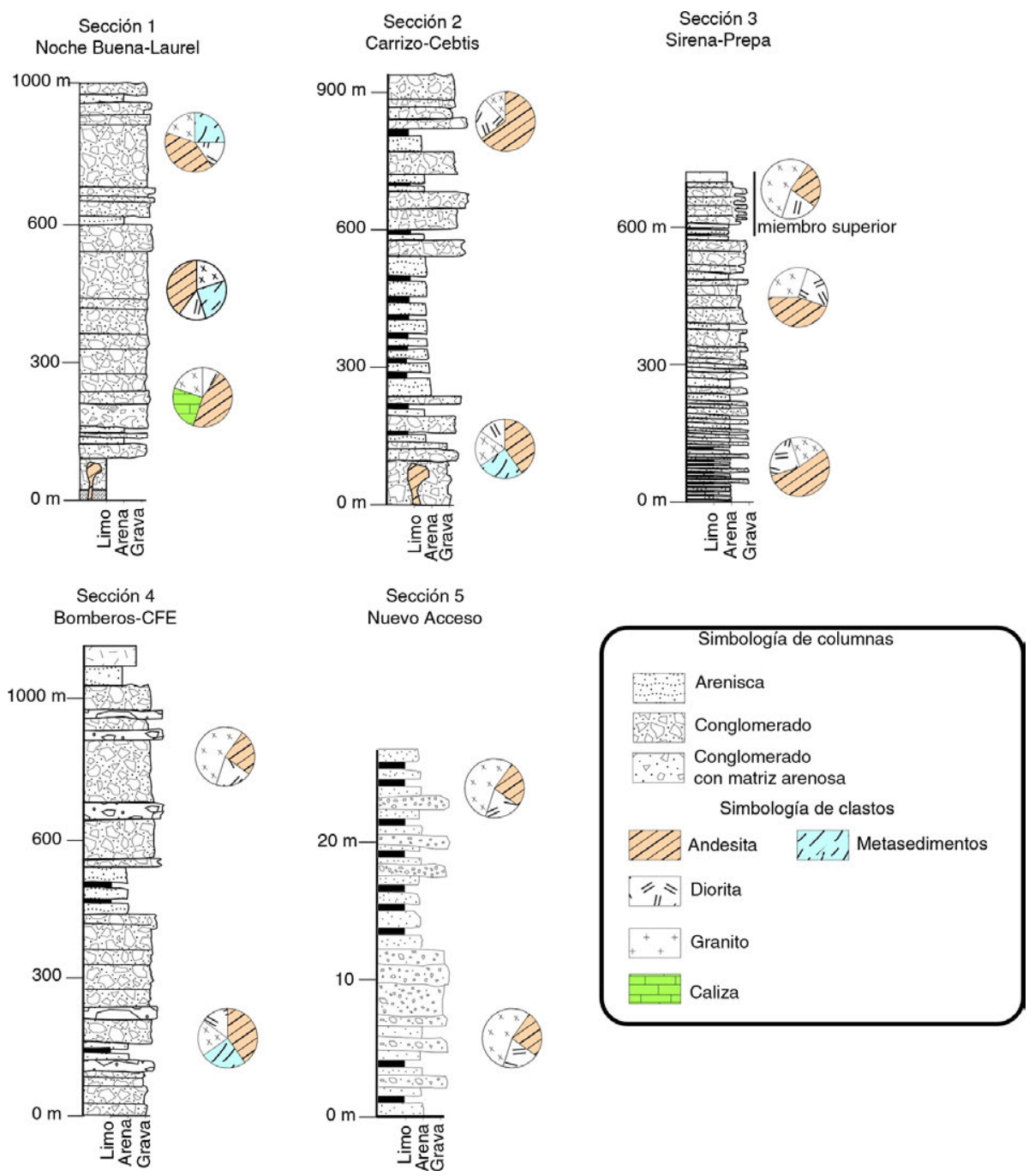

Fig. 4.-Columnas estratigráficas medidas en el Conglomerado Guanajuato. La ubicación de las columnas se indica en la Fig. 2. Las columnas 1, 2 y 4 se midieron en el miembro inferior. La columna 5 y parte superior de la 3 se midieron en el miembro superior. 

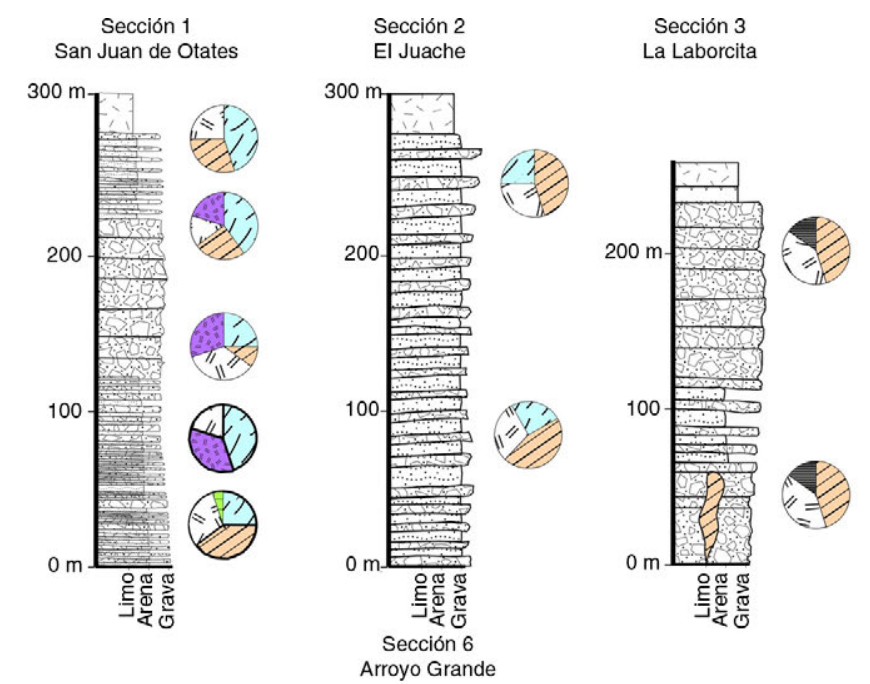

Sección 4
Arroyo Mastranto
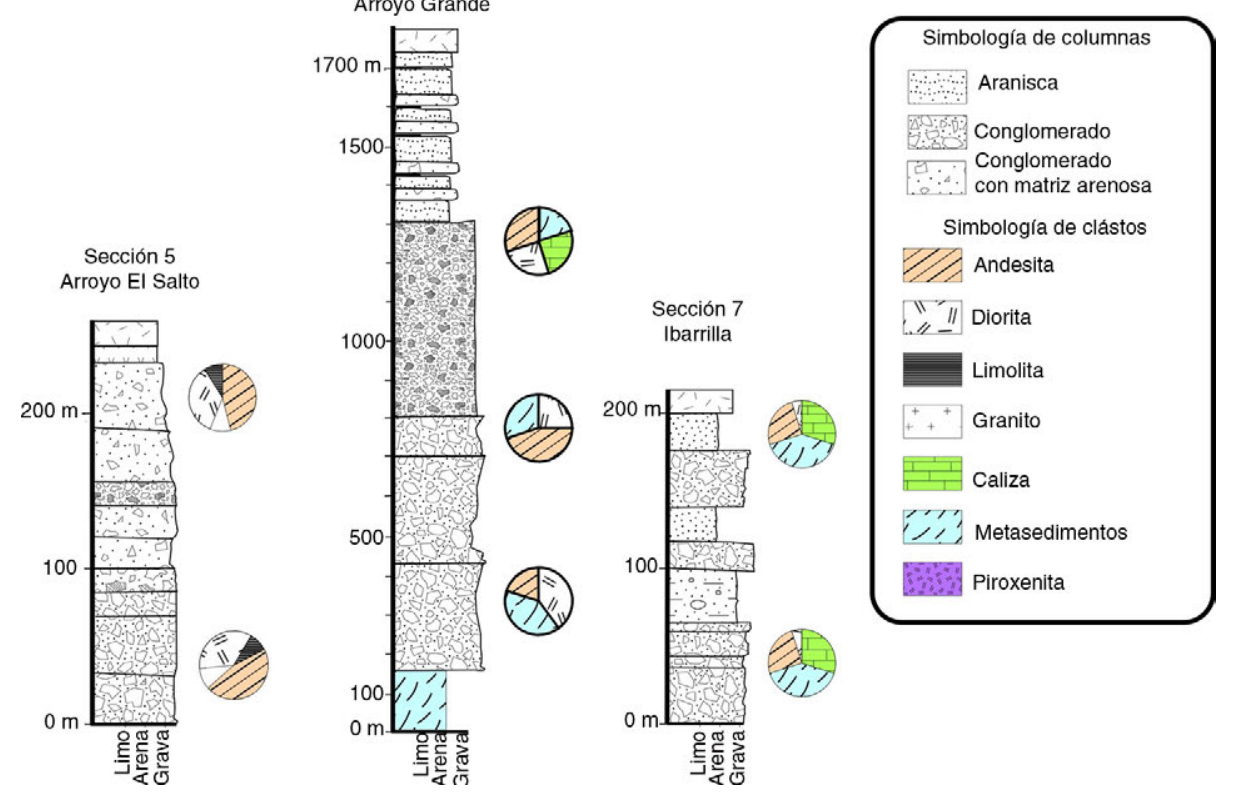

Fig. 5.-Columnas estratigráficas medidas en el Conglomerado Duarte. La ubicación de las columnas se indica en la Fig. 3.

conglomerados se encuentran de pobre a moderadamente seleccionados con clastos subangulares a subredondeados y gradación normal (Fig. 6). La fábrica de los conglomerados es soportada por clastos. Los estratos de conglomerado presentan una geometría cóncava con base erosiva y con sucesiones grano-decrecientes hacia arriba. En algunos casos, la litofacies $\mathrm{Gm}$ presenta estructuras de imbricación de clastos, por medio de las cuales fue posible la medición de dirección de paleocorriente. Los resultados obtenidos definen una dirección de transporte sedimentario hacia el SW $10^{\circ}-40^{\circ}$ y SE $10^{\circ}-50^{\circ}$ en la parte media del miembro inferior (Figs. 2 y 4). La litofacies Gms presenta estratos de 0.15 a $1 \mathrm{~m}$ de espesor, extendiéndose lateralmente por varias decenas de metros. Los clastos son de tamaño de las gravas, de $1 \mathrm{a} 10 \mathrm{~cm}$ y cantos de 10 a $28 \mathrm{~cm}$ soportados por una matriz de arena media a gruesa. La litofacies Gms es pobremente seleccionada con clastos y cantos principalmente volcánicos de forma subangular (Fig. 7). Las capas de litofacies Gms presentan generalmente base no erosiva con geometría tabular. Se encuentran intercaladas con las litofacies Gm. La litofacies Sgpc corresponden a conglomerados constituidos por gravas y bloques subangulares a subredondeados de 0.5 a $1 \mathrm{~m}$, pobremente seleccionados y soportados por clastos. Las capas presentan un espesor 
de 1.5 a $2 \mathrm{~m}$, geometría tabular y base erosiva. Presentan gradación normal y se encuentran intercaladas por facies Gms y Ss.

La litofacie Ss, consisten de litarenitas de grano medio a grueso de color rojizo, que presentan estratificación horizontal, "pebble cluster" y marcas de gotas de lluvia (Fig. 6). Los estratos de areniscas tienen un espesor de 20 a $60 \mathrm{~cm}$, extendiéndose lateralmente por varias decenas de metros. Los estratos presentan una geometría lenticular intercalada con facies de areniscas $(\mathrm{Sm})$ y de lutitas masivas (Fsm). Las litofacies de areniscas (Sm) se presentan en estratos de 20 a $60 \mathrm{~cm}$ de espesor, y están constituidas por areniscas de grano medio con escasos líticos volcánicos, su selección es moderada a pobre y presentan estratificación inversa. La litofacies de lutitas masivas (Fsm) presenta un color café a rojo vino con un espesor de 0.5 a 4 $\mathrm{cm}$. Presenta grietas de desecación (Fig. 6). Los estratos son continuos lateralmente por decenas
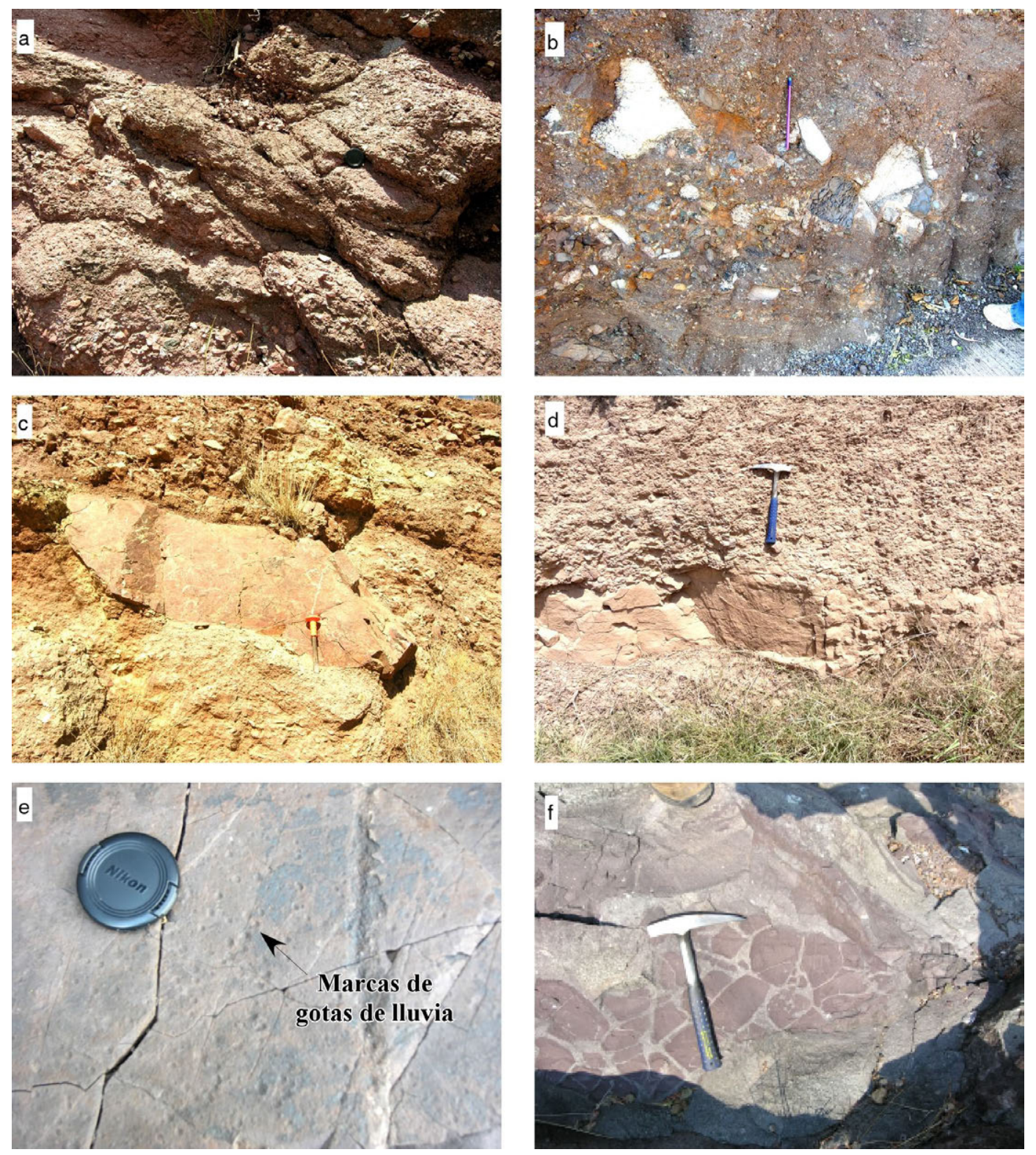

Fig. 6.-Litofacies del Conglomerado Guanajuato y Conglomerado Duarte. (a) Facies de conglomerados masivos (Gm). (b) Facies de flujos de gravedad (Gms). (c) Facies de flujos hiperconcentrados (Sgpc), la flecha indica un bloque de $80 \mathrm{~cm}$ de longitud. (d) Facies de arenisca (Ss). (e) Facies arenosas con impresiones de gotas de lluvia. (f) Facies de lutita (Fm) con grietas de desecación. 
de metros. Su geometría es tabular a lenticular, el tipo de superficie es plana, su relación con otras capas es paralela y está intercalado con litofacies de lutitas con estratificación laminar (Fl) y facies de areniscas (Ss).

\section{Miembro superior}

El miembro Superior del conglomerado Guanajuato está separado del miembro inferior por una discordancia erosiva de edad no determinada (Edwards, 1955) dicha discordancia puede observarse claramente en la ladera oeste del Cerro Sirena (Fig. 2). Está constituido predominantemente por litofacies de conglomerado (Gm, Gms, Sgpc) y en menor proporción litofacies de areniscas $(\mathrm{Sg})$ y litofacies de grano fino (Fsm, Fl) (Tabla 1). El rasgo más importante que permite diferenciar el miembro superior con el miembro inferior es la composición de los clastos ya que en el miembro superior los clastos graníticos son más abundantes que en el miembro inferior en el cual predominan los clastos volcánicos y metasedimentarios (Fig. 7). La litofacies Gm consisten de estratos de $0.5 \mathrm{~m}$ de conglomerado masivo, extendiéndose lateralmente por varias decenas de metros. Dichos conglomerados están constituidos por clastos de $0.5 \mathrm{a} 10 \mathrm{~cm}$, de forma subangular y de composición predominantemente volcánica y granítica. Su clasificación es pobre, con una matriz arenosa y fábrica soportada por clastos. La geometría de las capas presentan superficie de base erosiva y gradación normal. Los clastos se encuentran localmente imbricados indicando un transporte sedimentario hacia el SW $40^{\circ}-80^{\circ}$. La litofacies Gm se encuentra interestratificada con litofacies de conglomerado con bloques (Sgpc) y con litofacies de areniscas gruesas $(\mathrm{Sg})$. Las litofacies de conglomerados con bloques (Sgpc), corresponde a depósitos de $2 \mathrm{~m}$ de espesor y varias decenas de metros de longitud, constituidos por clastos de 1 a $10 \mathrm{~cm}$ hasta $1 \mathrm{~m}$. La forma de los clastos es sub-angular con fábrica soportada por clastos de composición volcánica y granítica. Estos estratos presentan una geometría tabular y una apariencia masiva. La litofacies de arenisca gruesa $(\mathrm{Sg})$, corresponde a estratos de areniscas medias a gruesas con clastos subangulares a subredondeados de 0.5 a 1 $\mathrm{cm}$. de composición predominantemente volcánica y granítica (Fig. 6). Esta facies de arenisca se encuentran intercalada por facies de lutita masivas (Fsm) de color café a rojo vino con espesores de 0.5 a $4.0 \mathrm{~cm}$ presentando grietas de desecación.

El límite superior del Conglomerado Guanajuato está cubierto concordantemente por la Formación Losero que corresponde a una arenisca fina de color verde oliva depositada en ambiente fluvial (PuyAlquiza et al., 2014) con niveles ricos en arenisca tobácea que a su vez subyace a la Riolita Bufa (33.53 +/- 0.48 Nieto-Samaniego et al., 2015) y que corresponden a la base de la cubierta volcánica Cenozoica.

\section{Conglomerado Duarte (CD)}

En el presente trabajo estudiamos siete localidades del municipio de León: Arroyo San Juan de Otates, El Juache, La Laborcita, Arroyo Mastranto, Arroyo El Salto, Ibarrilla y Arroyo Grande (Fig. 3). El espesor máximo medido para esta unidad es de 1700 m en Arroyo Grande dividiéndolo en miembro inferior y superior.

Las capas del CD tienen un rumbo promedio $\mathrm{N} 70^{\circ} \mathrm{W}$ con echados $55^{\circ}$ a $23^{\circ} \mathrm{NE}$. La inclinación de las capas disminuye de la base hacia la cima, con inclinaciones mayores en el extremo SE de los afloramientos estudiados (Fig. 3). En el extremo NW del área estudiada (Fig. 3) las capas presentan inclinaciones menores que van de $20^{\circ}$ a $7^{\circ} \mathrm{NE}$.

\section{Miembro inferior}

El miembro inferior del CD presenta un espesor de $1200 \mathrm{~m}$ y descansa discordantemente sobre el complejo basal. Muy cerca de su base fue intrusionado por un sill de andesita de $25 \mathrm{~m}$ de espesor. Se desconoce la edad precisa de estos cuerpos de andesita, sin embargo Ruiz-González (2015) reportó una ignimbrita en la base del $\mathrm{CD}$, la cual fechó por U-Pb en 48.8 Ma.

El miembro inferior fue descrito en las localidades de Arroyo San Juan de Otates, El Juache, La Laborcita, Arroyo Mastranto y Arroyo El Salto (Fig. 3). Está constituido predominantemente por una sucesión de conglomerados de la litofacies $\mathrm{Gm}$ intercalados con areniscas Ss. Los depósitos de conglomerado son de color rojizo con una estratificación incipiente a bien definida. La litofacies $\mathrm{Gm}$ se presenta en estratos de 0.7 a $2 \mathrm{~m}$ de espesor con continuidad lateral de decenas de metros y de forma lenticular con base erosiva. 
Tabla 1.-Tabla de litofacies del Conglomerado Guanajuato y Conglomerado Duarte, modificado de la clasificación de Miall (1996).

\begin{tabular}{|c|c|c|c|c|c|}
\hline Facies & Descripción & $\begin{array}{l}\text { Espesor } \\
\mathrm{m}\end{array}$ & $\begin{array}{l}\text { Constituyentes } \\
\text { principales }\end{array}$ & $\begin{array}{l}\text { Estructuras } \\
\text { sedimentarias }\end{array}$ & $\begin{array}{l}\text { Ambiente } \\
\text { de depósito }\end{array}$ \\
\hline Gms & $\begin{array}{l}\text { Gravas de } 1 \text { a } 10 \mathrm{~cm} \text { y cantos de } 10 \text { a } \\
28 \mathrm{~cm} \text { de longitud soportados en una } \\
\text { matriz de arena media a gruesa }\end{array}$ & $0.15-1$ & Líticos volcánicos & Ninguna & $\begin{array}{l}\text { Flujo de } \\
\text { escombro }\end{array}$ \\
\hline $\mathrm{Gm}$ & $\begin{array}{l}\text { Canal de gravas angulares de } 0.5 \\
\text { a } 5 \mathrm{~cm} \text { de composición polimíctica } \\
\text { predominando los de composición } \\
\text { volcánica, metasedimentaria y en } \\
\text { menor proporción los de composición } \\
\text { granítica }\end{array}$ & $0.17-2$ & $\begin{array}{l}\text { Líticos volcánicos, } \\
\text { metasedimentarios y } \\
\text { graníticos }\end{array}$ & $\begin{array}{l}\text { Gradación normal } \\
\text { imbrincación }\end{array}$ & Canales menores \\
\hline Sgpc & $\begin{array}{l}\text { Canal de gravas y bloques de } 0.5 \text { a } \\
1 \mathrm{~m} \text { de de forma angular a subangular, } \\
\text { pobremente seleccionados y } \\
\text { soportados por clastos }\end{array}$ & 2 & $\begin{array}{l}\text { Líticos volcánicos y } \\
\text { graníticos }\end{array}$ & Pebble Cluster & $\begin{array}{l}\text { Flujos } \\
\text { hiperconcentrados }\end{array}$ \\
\hline $\mathrm{Sg}$ & $\begin{array}{l}\text { Arena de grano medio a grueso, } \\
\text { constituida por líticos angulares de } 0.5 \\
\text { a } 1 \mathrm{~cm} \text {, de composición volcánica }\end{array}$ & $0.20-0.60$ & Líticos volcánicos & Pebble Cluster & $\begin{array}{l}\text { Canales de } \\
\text { erosión } \\
\text { relleno }\end{array}$ \\
\hline $\mathrm{Sm}$ & $\begin{array}{l}\text { Arena de grano medio, presenta líticos } \\
\text { de composición volcánica }\end{array}$ & $0.20-0.60$ & Líticos volcánicos & Gradación inversa & $\begin{array}{l}\text { Depósitos de } \\
\text { Flujos de } \\
\text { gravedad }\end{array}$ \\
\hline Ss & $\begin{array}{l}\text { Arena de grano medio a grueso, } \\
\text { presenta líticos de composición } \\
\text { volcánica }\end{array}$ & $0.20-0.60$ & Líticos volcánicos & Gotas de lluvia & Barras \\
\hline Sh & $\begin{array}{l}\text { Arena de grano medio, con líticos } \\
\text { de composición volcánica }\end{array}$ & $0.20-0.60$ & Líticos volcánicos & $\begin{array}{l}\text { Estratificación } \\
\text { horizontal }\end{array}$ & Barras \\
\hline Sf & $\begin{array}{l}\text { Arena fina, con líticos de composición } \\
\text { volcánica }\end{array}$ & $0.20-0.60$ & Líticos volcánicos & Masiva & Barras \\
\hline Fsm & Limo-arcilla & 0.5 & & $\begin{array}{l}\text { Grietas de } \\
\text { desecación }\end{array}$ & $\begin{array}{l}\text { Planicie de } \\
\text { inundación }\end{array}$ \\
\hline $\mathrm{FI}$ & Limo-arcilla & 0.5 & & $\begin{array}{l}\text { Estratificación } \\
\text { laminar }\end{array}$ & $\begin{array}{l}\text { Planicie de } \\
\text { inundación }\end{array}$ \\
\hline
\end{tabular}

Los clastos que constituyen la litofacies Gm son de 5 a $7 \mathrm{~cm}$ de composición andesítica, diorítica, riolítica, calizas y granito (Fig. 7). En la parte media del miembro inferior es notable la abundancia de clastos de piroxenita en la localidad La Laborcita (Fig. 3). La litofacies Gm se encuentra pobre a moderadamente seleccionada con clastos sub-angulares a sub-redondeados (Fig. 6). La fábrica de la litofacies Gm es soportada por clastos con gradación normal. Los clastos se encuentran localmente imbricados con una dirección de transporte sedimentario hacia el SW $20^{\circ}-65^{\circ}$. Es importante resaltar que hacia la cima del miembro inferior, en el Arroyo Mastranto y Arroyo E1 Salto (Fig. 3), la dirección del transporte sedimentario cambia a SE $15^{\circ}-40^{\circ}$. Este cambio en la dirección de paleocorriente está asociado a un cambio en la composición de los clastos de los conglomerados, ya que incrementa el porcentaje de clastos de caliza en un $12 \%$. La litofacies Ss está representada por areniscas de grano medio a grueso de color rojizo de composición litarenítica en su mayoría volcánica (líticos de andesita, riolita, diorita). Se presentan en estratos de 35 a $90 \mathrm{~cm}$ de espesor. Localmente contiene estructuras de Pebble Cluster en donde los clastos exhiben un tamaño de hasta $40 \mathrm{~cm}$, generalmente de composición volcánica, granítica y piroxenítica inmersos en una matriz arenosa.

\section{Miembro superior}

El miembro superior tiene un espesor de $400 \mathrm{~m}$ y descansa concordantemente sobre el miembro inferior. Está constituido predominantemente por litofacies de areniscas Sg y lutitas Fsm de color gris a café rojizo. Lateralmente hacia el NW se incrementa el contenido de conglomerados $(\mathrm{Gm})$ y areniscas $(\mathrm{Ss})$, observables en la localidad de Ibarrilla. Las areniscas $(\mathrm{Sg})$ corresponden a capas de areniscas medias a 


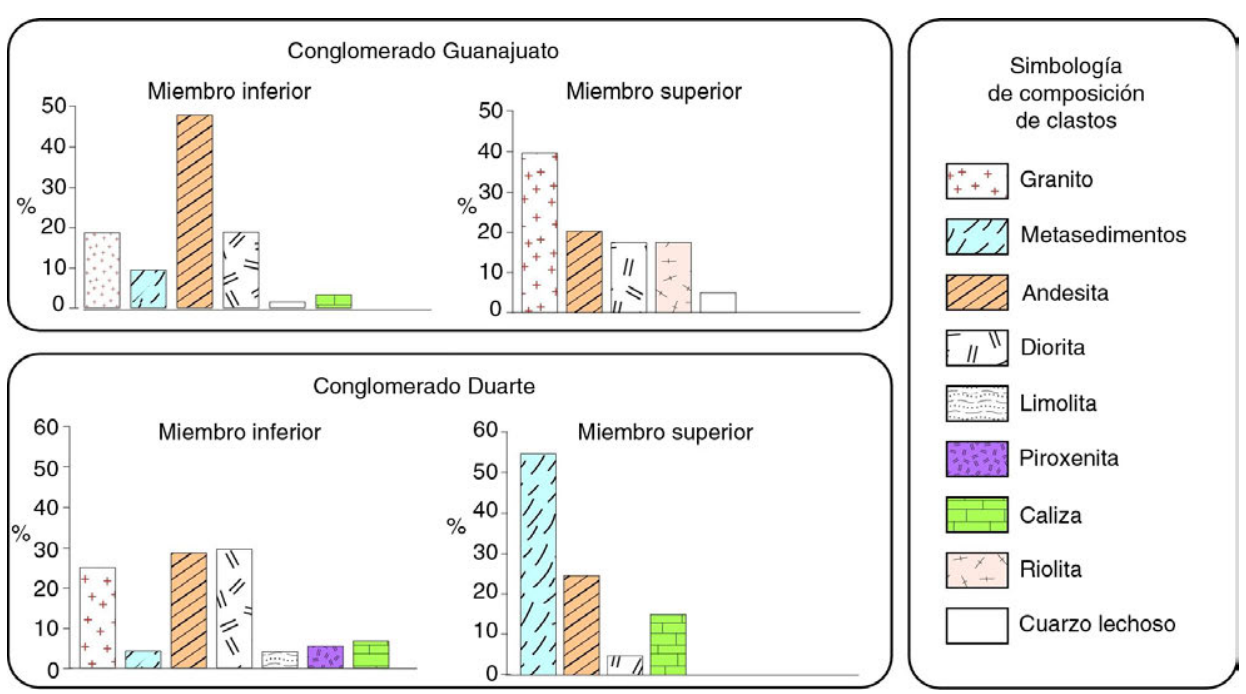

Fig. 7.-Graficas de porcentaje de composición de clastos en el Conglomerado Guanajuato y el Conglomerado Duarte.

gruesas con clastos de 0.5 a $1 \mathrm{~cm}$. Las litofacies de lutitas masivas (Fsm) presentan un color café a gris claro con espesores de 0.5 a $4 \mathrm{~cm}$. Presentan grietas de desecación, mostrando los límites de sus polígonos bien desarrollados. Los estratos son continuos lateralmente por decenas de metros.

Los conglomerados $(\mathrm{Gm})$ tienen espesores de 0.5 a $3 \mathrm{~m}$ de forma lenticular y continuidad lateral de decenas de metros. Los clastos son de 3 a $7 \mathrm{~cm}$, subangulares a subredondeados, de pobre a moderadamente seleccionados y composición predominantemente metamórfica (filitas, cuarcitas), de caliza y clastos ígneos (andesita, riolita y diorita). La fábrica es soportada por clastos con gradación normal.

\section{Análisis petrográfico de clastos de caliza}

\section{Conglomerado Guanajuato (CG)}

Edwards (1955) reportó la existencia de clastos de calizas con láminas de pedernal y un clasto de caliza fosilífera en el CG. El clasto de caliza fosilífera contiene fósiles de coral silicificado Stylina (Heliocoenia) sp., Myriophyllia sp. (grupo de M.rinitatis) y Drandraraea que fue determinado como del Jurásico Superior-Cretácico Inferior. Edwards (1955) no reportó la ubicación o posición estratigráfica del estrato del clasto de caliza fosilífera, por lo que durante el desarrollo del conteo composicional de clastos se prestó especial atención en el conteo y muestreo de clastos de caliza considerando que aportan información relevante sobre la geología del área fuente. El miembro inferior del CG presenta un $12 \%$ de clastos de calizas. Tomando en cuenta lo anterior y considerando que las calizas pueden aportar información en relación a la edad y ambiente sedimentario de las rocas del área fuente, se realizó un análisis petrográfico de dichos clastos.

Un total de 125 clastos de calizas fueron colectados y analizados petrográficamente, de los cuales el $20 \%$ corresponden a calizas de plataforma somera y el $80 \%$ a calizas de ambiente de cuenca. Los clastos de calizas de plataforma somera presentan una forma sub-angular, sub-redondeada a redondeada, tamaño variable de 7 a $50 \mathrm{~cm}$ y color gris claro. Los clastos corresponden a packstone, wackestone (Fig. 8) y grainstone. Los clastos con textura wackestone son los más abundantes. Estos clastos se caracterizan por contener bioclastos, intraclastos micríticos laminares y material detrítico en una matriz micrítica. Los bioclastos están representados por fragmentos esqueletales de bivalvos, braquiópodos, gasterópodos, equinodermos y foraminíferos (Pseudocyclammina lituus, Everticyclammina virguliana, Pfenderina neocomiensis, Neotrocholina valdensis, Montsalvenia salevensis y Glomospira sp.) del BerriasianoValanginiano reportados previamente por los autores en Omaña et al. (2015). Se observan de igual manera granos no esqueletales como oolitos y peloides. Los oolitos presentan forma esférica a elipsoidal de 0.25 a $2.00 \mathrm{~mm}$ de diámetro, con un núcleo predominantemente de cuarzo detrítico. Los peloides son de forma 
esférica a ovoide de 0.03 a $0.3 \mathrm{~mm}$ de diámetro y a diferencia de los oolitos, no presentan estructura interna. Los fragmentos detríticos presentan forma sub-angular de 1 a $3 \mathrm{~mm}$ de longitud, representados por cuarzo, plagioclasas, minerales opacos, líticos volcánicos (andesita) y líticos sedimentarios (limolita). Los clastos de calizas de cuenca son sub-angulares a sub-redondeados de 5 a $7 \mathrm{~cm}$ de diámetro con una coloración gris oscura. La textura predominante es mudstone laminar y masiva con presencia de calcisferúlidos inmersos en una matriz de micrita con cemento de esparita. Por comparación y similitud de estas facies con las facies calcáreas de la Sierra de Guanajuato, las consideramos como pertenecientes a las facies micríticas de la Formación Valenciana del Berriasiano-Hauteriviano, descritas por Martini et al. (2013) como estratos de micrita laminares alternados con debris flow.

Análisis petrográfico de clastos de caliza del Conglomerado Duarte (CD)

Un total de 100 clastos de calizas fueron colectados y analizados petrográficamente. Todas las muestras fueron colectadas en el miembro inferior del conglomerado Duarte. Todos los clastos analizados corresponden a mudstone laminares y/o masivas. Los clastos son de 5 a $20 \mathrm{~cm}$ con forma sub-redondeada a redondeada, de color gris obscuro. Las calizas estudiadas corresponden a microfacies de mudstone de calcisferúlidos (Fig. 8). Es común observar calciesferas de $0.5 \mathrm{~mm}$ de diámetro de forma concéntrica y cristales de pirita. Estos clastos muestran evidencias de deformación representadas por estilolitas y fracturas de tensión rellenas de calcita y calcedonia.

\section{Discusión}

\section{Ambiente de depósito del CG}

Las litofacies dominantes del CG son: 1) conglomerados con matriz soportada Gms, que se interpretan como depósitos de flujos de escombro, y 2) conglomerados y areniscas con gradación normal $\mathrm{Gm}$, los que se interpretan como depósitos generados por transporte de carga de fondo. En su conjunto dichas litofacies se interpretan como el registro estratigráfico de un abanico aluvial en su parte media del modelo tipo II sensu Blair \&
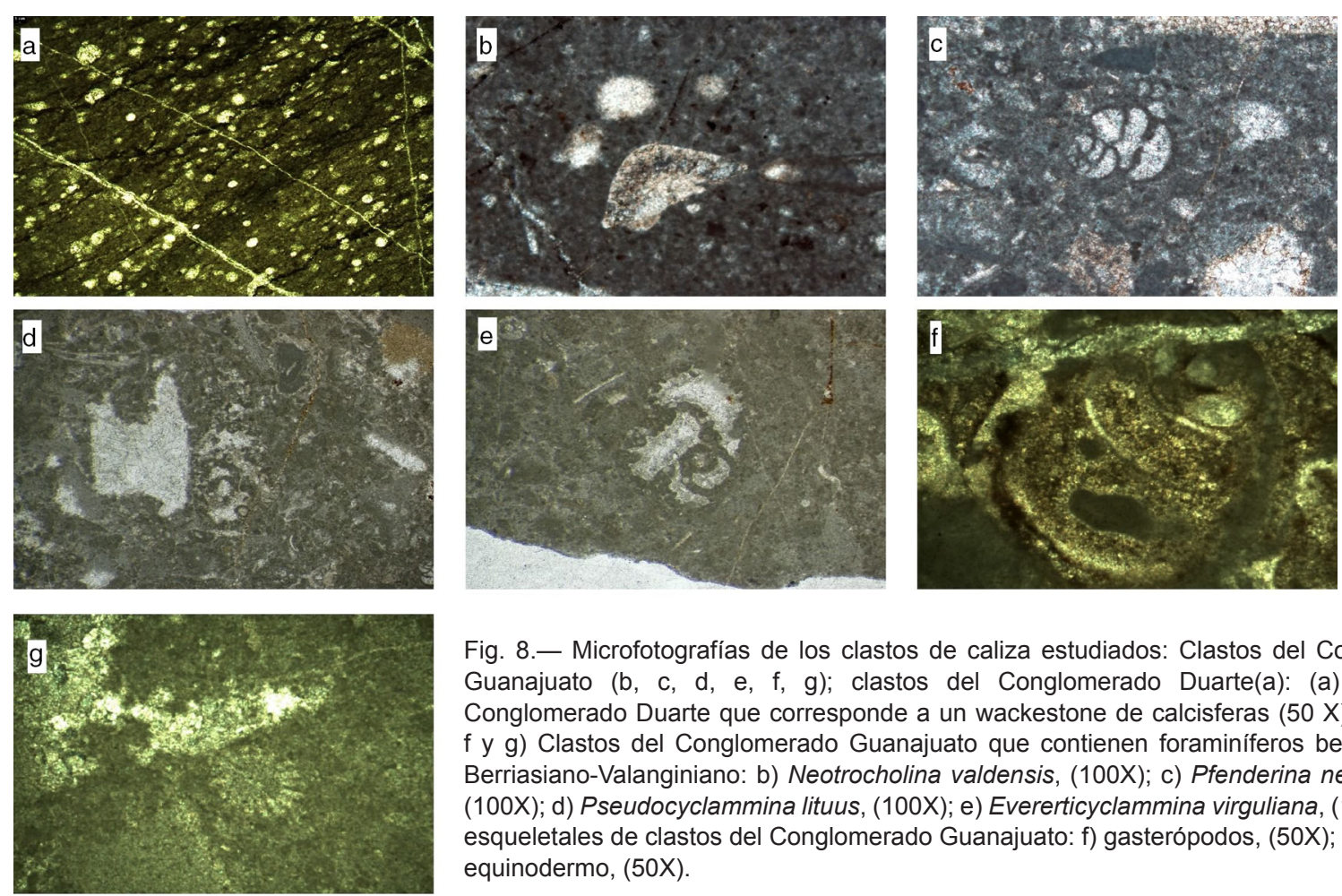

Fig. 8.- Microfotografías de los clastos de caliza estudiados: Clastos del Conglomerado Guanajuato (b, c, d, e, f, g); clastos del Conglomerado Duarte(a): (a) Clasto del Conglomerado Duarte que corresponde a un wackestone de calcisferas (50 X). (b, c, d, e, f y g) Clastos del Conglomerado Guanajuato que contienen foraminíferos bentónicos del Berriasiano-Valanginiano: b) Neotrocholina valdensis, (100X); c) Pfenderina neocomiensis, (100X); d) Pseudocyclammina lituus, (100X); e) Evererticyclammina virguliana, (100X). Otros esqueletales de clastos del Conglomerado Guanajuato: f) gasterópodos, (50X); g) espina de equinodermo, (50X). 
McPherson, (1994). De acuerdo con este escenario las litofacies Gms, Sgpc y Sm son producto de flujos hiperconcentrados influenciados inercialmente por la gravedad (Blair \& McPherson, 1994), lo que evidencia la existencia de paleotopografías elevadas en la zona de aporte de sedimentos. Del análisis de la columna del CG puede interpretarse una mayor canalización de la escorrentía superficial en el miembro superior, donde dominan las facies de canales fluviales $\mathrm{Gm}$ de drenaje trenzado, en contraste con el miembro inferior donde además de conglomerados existen facies de arenas ( $\mathrm{Sg}, \mathrm{Sm}, \mathrm{Ss}, \mathrm{Sh}, \mathrm{Sf})$ y facies finas no canalizadas (Fsm y Fl), que sugiere un ambiente de sedimentación continental de abanico aluvial en su parte media y distal del modelo de Blair \& McPherson (1994).

\section{Ambiente de depósito del CD}

En el miembro inferior del CD predominan litofacies de conglomerado Gm y areniscas Ss, las cuales se interpretan como el relleno de canales con gravas masivas que resultan de flujos con alta carga de sedimento que al disminuir su velocidad depositaron arenas Ss. Estos flujos pueden ser denominados "sheet-flood slurries" (Nemec \& Muszynski, 1982) flujos laminares masivos (densos), que son interpretados como flujos que se encuentran entre "debris flow" flujos de escombros y flujos turbulentos fluviales, los cuales son comunes en la parte media de un abanico aluvial (tipo II sensu Blair \& McPherson, 1994).

En el miembro superior predominan las litofacies Sg que gradan lateralmente hacia el noroeste a facies $\mathrm{Gm}$ y Ss. Las litofacies de areniscas $\mathrm{Sg}$ se interpretan como resultado de flujos laminares que lateralmente y en periodos con flujos supercríticos depositan arenas gruesas y gravas en la base de canales donde las arenas corresponden a barras que separan canales trenzados de la parte media a distal del abanico aluvial, mientras que hacia el NW las litofacies Gm, son canalizadas y de más alta energía, ubicados en la parte media del abanico aluvial. La columna estratigráfica general del CD es grano-decreciente, donde el miembro inferior se desarrolló en un ambiente de abanico aluvial medio, mostrando un retroceso de la fuente hacia el miembro superior que está representada por facies de areniscas de barras que evidencian menor energía de transporte.

\section{Evolución tectono-sedimentaria}

La presencia de litofacies relacionadas con flujos de gravedad (Gms, Sgpc y Sm) y el basculamiento de las capas interpretado como sindepositacional por Aranda-Gómez y McDowell (1998), sustentan la existencia de pulsos de actividad tectónica y subsidencia durante el Eoceno.

Las direcciones de paleocorriente $\mathrm{SW} 10^{\circ}-40^{\circ}$ y SE $10^{\circ}-50^{\circ}$ en la parte media del miembro inferior del CG sustentan la existencia de bloques levantados al NE y NW de la ciudad de Guanajuato así como subsidencia de la cuenca asociada a un basculamiento hacia el NE, soportado por la dirección del echado de la estratificación (Figs. 2 y 9) y reportado por Aranda-Gómez y McDowell (1998).

La discordancia angular entre el miembro inferior y superior del CG marcan el levantamiento de bloques al NE de la ciudad de Guanajuato. El levantamiento de bloques generó flujos con dirección SW $40^{\circ}-80^{\circ}$ que al mismo tiempo produjo subsidencia asimétrica de la cuenca, hacia el ESE evidenciada por el basculamiento de las capas y un mayor espesor del miembro superior el cual se acuña al sur de la Ciudad de Guanajuato (Figs. 2 y 9).

Durante la sedimentación del miembro inferior del CD existió levantamiento de bloques al NNE, evidenciado por la dirección de flujo de clastos imbricados SW $20^{\circ}-65^{\circ}$ y subsidencia mayor hacia el SE del área estudiada, lo cual se evidencia al existir mayor inclinación de capas en esta área $\left(26^{\circ}-55^{\circ}\right)$ y dirección del echado al NNE (Figs. 3 y 9). En la cima del miembro inferior la proporción de clastos de caliza se incrementa, al mismo tiempo la dirección de transporte sedimentario cambia de SW $20^{\circ}-65^{\circ}$ a SE $15^{\circ}-40^{\circ}$ (Figs. 3 y 5). Este cambio en la dirección y composición del aporte de sedimento lo interpretamos como producto del levantamiento de la Sierra de Guanajuato hacia el NNW y al mismo tiempo el retroceso hacia el NW del área fuente, evidenciado por el establecimiento del miembro superior con facies más distales de abanico, tales como areniscas de barras y lutitas de planicie de inundación (Fig. 9). Esto también es sustentado por el cambio 


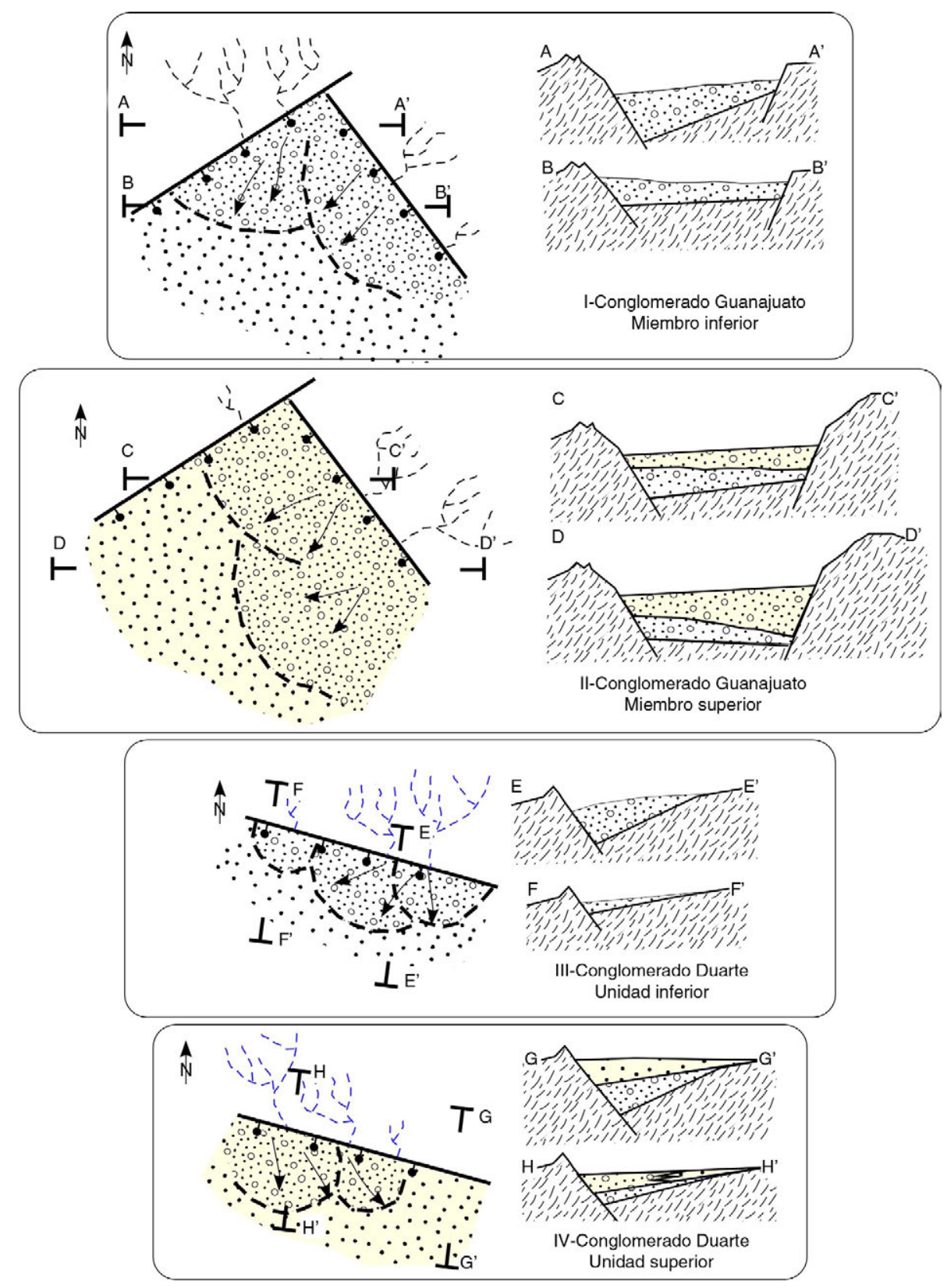

Fig. 9.- Representación esquemática de la evolución tectonosedimentaria del Conglomerado Guanajuato y el Conglomerado Duarte durante el Eoceno. I) y II) Depositación asimétrica del Conglomerado Guanajuato; II) y IV) Depósito del Conglomerado Duarte con subsidencia asimétrica de un medio graben.

lateral de facies de conglomerado al W (Ibarrilla) y facies de areniscas al E (Arroyo Grande).

La estratigrafía de los depósitos de abanicos aluviales puede ser controlada por factores internos o externos a la cuenca. En el caso de los depósitos de abanico aluvial estudiados, consideramos que los factores externos tales como el clima o la litología del área fuente jugaron un papel secundario en la geometría o el tipo de facies. En relación al clima existen evidencias que nos permiten suponer un clima semiárido evidenciado por grietas de desecación, marcas de gota de lluvia en facies finas de planicie de inundación, descartamos un clima totalmente desértico, ya que no existen evaporitas ni desarrollo de paleosuelos con horizontes de caliche típicos de desierto. Por otra parte en todas las litofacies identificadas existe muy 
poca arcilla que pudiera ser atribuida al producto de intemperismo de rocas en climas húmedos.

El control tectónico parece ser más importante, considerando el basculamiento de las capas durante el depósito de las facies de conglomerados con clastos sub-angulares que son evidencia de transporte corto. Lo anterior ha sido demostrado en estudios experimentales numéricos donde exponen que el control tectónico de fallas activas en sistemas de abanico aluvial tiene mayor influencia en la sedimentación comparado con la influencia de factores climáticos (Allen y Densmore, 2000).

ElCGy elCD fueron depositados entre el Ypresiano (Eoceno temprano) y el Rupeliano (Oligoceno temprano), por lo que ambos corresponden a depósitos clásticos pos-Laramide y pre-vulcanismo Sierra Madre Occidental.

Con base en los datos sedimentológicos, estratigráficos y el basculamiento sin-sedimentario de capas se interpreta que existió espacio disponible generado por distensión y/o transtension durante el depósito del CG y el CD. La geometría de los estratos y las discontinuidades internas tales como la discordancia entre el miembro inferior y el miembro superior del CG, ponen en evidencia la existencia de mayor actividad tectónica durante el depósito del CG comparado con el depósito del CD. Las fallas que limitan actualmente los afloramientos de los depósitos estudiados no corresponden a las fallas maestras que limitaron la zona fuente de las cuencas de depósito, considerando que las facies que bordean las fallas Veta Madre y Falla Aldana (en el CG) y la Falla del Bajío (en el CD), no presentan facies de brechas con bloques angulares, flujos de escombro o fallamiento sinsedimentario en las proximidades de ellas. Las fallas maestras que controlaron la sedimentación probablemente están sepultadas por la cubierta volcánica Cenozoica.

\section{Implicaciones paleogeográficas de clastos de caliza}

Los depósitos clásticos del CG y CD son producto de la erosión de bloques levantados durante el Eoceno. Este pulso de levantamiento de bloques es puesto en evidencia por el inicio de la erosión de las rocas del complejo basal de la Sierra de Guanajuato. En el miembro inferior del CG predominan clastos de composición andesítica y diorítica en un $66.8 \%$ y en un $12 \%$ de clastos de caliza. En el miembro superior predominan los clastos de granito con un $39.5 \%$, que evidencian el cambio de fuente de aporte por el levantamiento de bloques al NE de la ciudad de Guanajuato. En el CD predominan clastos de granito, diorita y piroxenita que corresponden a la litología existente en el bloque levantado del complejo basal al norte de los afloramientos estudiados. La parte superior del miembro inferior del CD presenta un incremento en los clastos de caliza y al mismo tiempo la dirección de transporte sedimentario cambia al SE $15^{\circ}-40^{\circ}$, que son prueba de un levantamiento mayor de la Sierra de Guanajuato hacia el NNW con respecto a la porción SE.

Los clastos de caliza aportan información en cuanto a la procedencia, ambiente de depósito y edad. Por lo que, de acuerdo al marco geológico regional de la Sierra de Guanajuato, las facies de calizas depositadas en la cuenca Arperos corresponden a facies de cuenca consideradas del Valanginiano-Turoniano (Dávila-Alcocer and Martínez-Reyes, 1987) y más recientemente restringidas al Berriasiano-Hauteriviano por Martini et al. (2011). Estas calizas de cuenca y rocas volcano-sedimentarias fueron afectadas por 3 eventos contráctiles pre-Albianos (Martini et al., 2013) y un cuarto evento compresivo posterior relacionado con la orogenia Laramide. De acuerdo al análisis de clastos de caliza del CG y CD, se subdividieron en dos grupos: uno representado por muestras con textura wackestone, packstone y grainstone; otro por muestras con textura mudstone con calcisferúlidos.

Las muestras con textura wackestone, packstone y grainstone con contenido de foraminíferos, oolitos y peloides indican un ambiente marino de aguas someras. Además aportan información en cuanto al ambiente sedimentario y configuración paleogeografica de la cuenca Arperos. El 20\% de los clastos analizados corresponden a calizas de plataforma somera con fragmentos esqueletales de bivalvos, braquiópodos, gasterópodos, equinodermos y foraminíferos bentónicos (Pseudocyclammina lituus, Everticyclamina virguliana, Pfenderina neocomiensis, Neotrocholina valdensis, Montsalvenia salevensis, y Glomospira sp.) del BerriasianoValanginiano de los cuales se describe en detalle en Omaña et al. (2015) (Fig. 8). Por otra parte Edwards (1955) reportó la existencia de clastos 
de calizas con láminas de pedernal y un clasto de caliza fosilífera que contenía fósiles de coral silicificado Stylina (Heliocoenia) sp., Myriophyllia sp. (grupo de M. rinitatis) y Drandraraea que corresponden al Jurásico Superior-Cretácico Inferior. La presencia de estos clastos de calizas de plataforma somera del Berriasiano-Valanginiano indica que existieron afloramientos de calizas someras, pertenecientes probablemente al límite occidental de la cuenca Arperos, dado el mismo intervalo de edad. Es importante hacer notar que la forma de los clastos de calizas corrobora este supuesto, considerando que muchos clastos son subangulares o subredondeados por lo que Edwards (1950) supuso un transporte de no más de $10 \mathrm{Km}$ del área de procedencia. Por otra parte, nosotros estimamos un transporte por carga de fondo de entre 3 a 15 $\mathrm{km}$ que corresponde a distancias estimadas para clastos de calizas en casos naturales y experimentales compilados por Mills (1979). En la revisión bibliográfica realizada no encontramos reportes de afloramientos de facies someras BerriasianoValanginiano, en la Sierra de Guanajuato. Por lo que el reporte de estos clastos de calizas someras deja abierta la posibilidad de la existencia de afloramientos de dichas facies en la Sierra de
Guanajuato. Los clastos de caliza somera fueron depositados en un intervalo de edad (BerriasianoValanginiano) comparable a las rocas de la cuenca Arperos, por lo que sugerimos formaron parte de los márgenes de la misma.

El grupo de muestras mudstone con calcisferúlidos indican un ambiente marino de cuenca o plataforma externa de baja energía La presencia de pirita en algunos clastos permiten interpretar condiciones anóxicas y reductoras. Para mudstones con calcisferúlidos no contamos con edad, por lo que el único argumento para correlacionarlas con formaciones conocidas, es su origen de cuenca marina. Es probable que las calizas de ambiente de cuenca sean producto de la erosión de la Formación Arperos y/o Formación Valenciana del Berriasiano-Hauteriviano (Martini et al., 2011). Cabe mencionar que en los clastos de caliza estudiados no encontramos facies Albianas o contemporáneas a la Caliza La perlita.

\section{Conclusiones}

El presente trabajo se enfoca en el estudio sedimentológico y composicional del Conglomerado Duarte (CD) y el Conglomerado Guanajuato (CG) depositados entre el Ypresiense (Eoceno temprano) y el

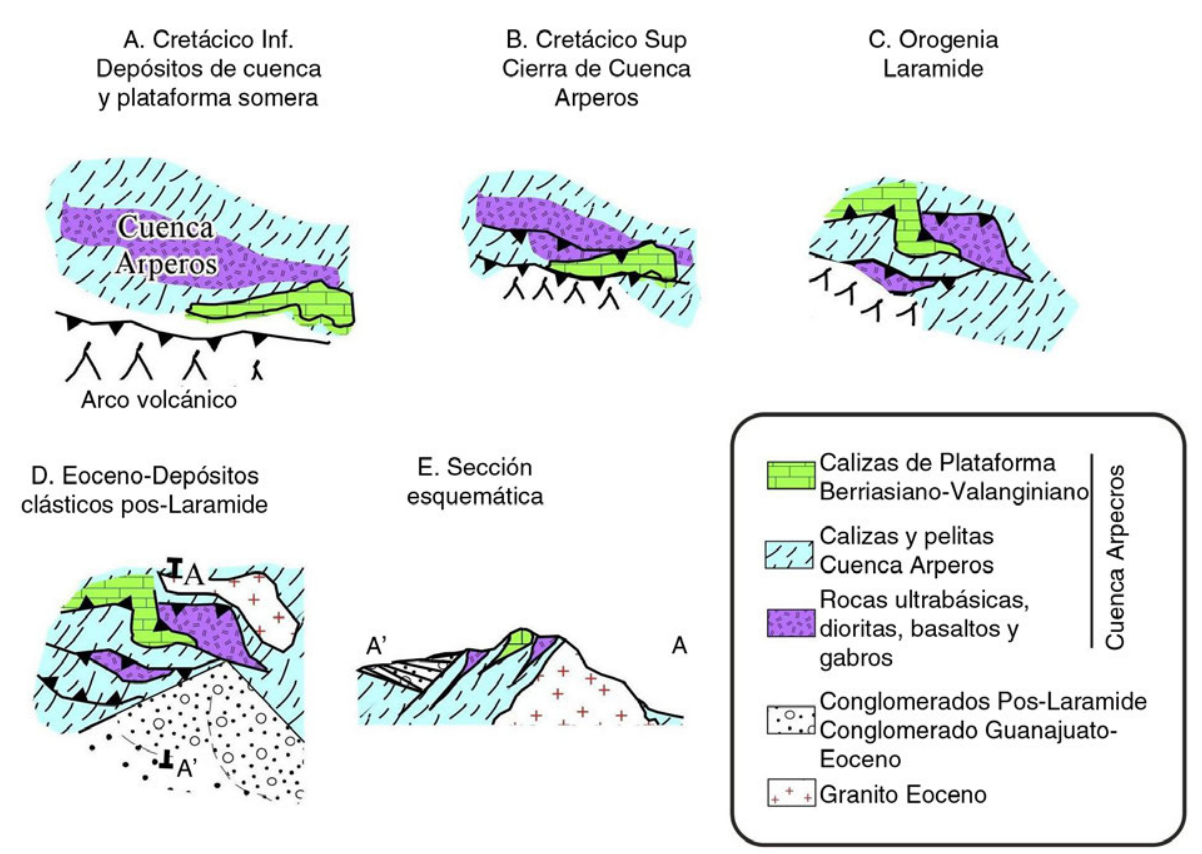

Fig. 10.- Interpretación generalizada explicando la coexistencia de calizas de plataforma y profundas de la cuenca Arperos (Jurásico superior-Cretácico inferior). Interpretado con base en los clastos encontrados en el Conglomerado Guanajuato. 
Rupeliense (Oligoceno temprano) en la Mesa Central Mexicana. Con base en el análisis sedimentológico, se interpretó que fueron depositados en un ambiente continental de abanico aluvial en su parte media y distal del modelo de Blair \& McPherson (1994).

El basculamiento de las capas y la dirección de flujo interpretada con la imbricación de clastos, sustentan la existencia de pulsos de actividad tectónica que levantaron bloques de la Sierra de Guanajuato al NE y NW de los afloramientos estudiados. Los clastos de caliza aportaron información en cuanto a la procedencia, ambiente de depósito y corroborando reportes previos de edad. Por lo que, de acuerdo al contenido de foraminíferos bentónicos en los clastos de caliza, la facies somera fueron depositadas en un intervalo de edad (Berriasiano-Valanginiano) comparable a las rocas de la cuenca Arperos, por lo que sugerimos formaron parte de los márgenes de la misma.

Los nuevos datos sedimentológicos y composicionales aportan información para entender el levantamiento y erosión, pre y pos-Laramide de la Sierra de Guanajuato en la Mesa Central Mexicana (Fig. 10).

\section{AGRADECIMIENTOS}

Agradecemos las sugerencias y comentarios de dos revisores anónimos, quienes contribuyeron grandemente a hacer de nuestro manuscrito e investigación una contribución científica de mejor calidad. También se agradece el apoyo brindado por el Laboratorio de Investigación y Caracterización de Minerales y Materiales (LICAMM-UG).

\section{Referencias}

Aguirre-Díaz, G.J.; Nelson, S.A.; Ferrari, L. \& LópezMartínez, M. (1997). Ignimbrites of the central Mexican Volcanic Belt, Amealco and Huichapan calderas (Querétaro-Hidalgo): excursión 1. In: Aguirre-Díaz, G.J.; Aranda-Gómez, J.J.; Carrasco-Núñez, G. \& Ferrari, L. (Eds.). Magmatism and tectonics of central and northwestern Mexico: a selection of the 1997 IAVCEI General Assembly excursions. UNAM, Instituto de Geología, México, D.F., 1-39.

Allen A.P. \& Densmore A.L. (2000). Sediment flux from an upliftingfaultblock. BasinResearch, 12(3-4):367-380. http://dx.doi.org/10.1111/j.1365-2117.2000.00135.x

Aranda-Gómez, J.J. \& McDowell, F.W. (1998). Paleogene extension in the southern Basin and Range
Province of Mexico; syndepositional tilting of Eocene Red Beds and Oligocene volcanic rocks in the Guanajuato Mining District. International Geology Review, 40 (2): 116-134. http://dx.doi. org/10.1080/00206819809465201

Aranda-Gómez, J.J.; Godchaux, M.M.; Aguirre-Díaz, G.J.; Bonnichsen, B. \& Martínez-Reyes, J. (2003). Three superimposed volcanic arcs in the southern cordillera-from the early cretaceous to the Miocene, Guanajuato, México. Field trip 6. In: Geologic transects across Cordilleran Mexico, Guidebook for the field trips of the 99th Geological Society of America Cordilleran Section Annual Meeting, Puerto Vallarta, Jalisco, Mexico, April 5-8, 2003. UNAM, Instituto de Geología, México, 123-168.

Aranda-Gómez, J.J.; Molina-Garza, R.; McDowell, F.W.; Vassallo-Morales, L.F.; Ortega-Rivera, M.A.; Solorio-Munguía J.G. \& Aguillón-Robles, A. (2007). The relationships between volcanism and extension in the Mesa Central: the case of Pinos, Zacatecas, Mexico. Revista Mexicana de Ciencias Geológicas, 2: 216-233.

Blair, T.C. \& McPherson, J.G. (1994). Alluvial fans and their natural distinction from rivers based on morphology, hydraulic processes, sedimentary processes, and facies assemblages. Journal of sedimentary research, 64 (3a): 450-489. http://dx.doi.org/10.1306/ D4267DDE-2B26-11D7-8648000102C1865D

Botero-Santa, P.A.; Alaniz-Álvarez, S.A.; Nieto-Samaniego, A.F.; López-Martínez, M.; Levresse, G.; Xu, S. \& Ortega-Obregón, C. (2015). Origen y desarrollo de la cuenca El Bajío en el sector central de la Faja Volcánica Transmexicana. Revista Mexicana de Ciencias Geológicas, 32 (1): 84-98.

Botsford, C.W. (1909). The Zacatecas district and its relation to Guanajuato and other camps. The Engineering and Mining Journal, 87: 1227-1228.

Centeno-García, E.; Guerrero-Suastegui, M. \& Talavera-Mendoza, O. (2008). The Guerrero Composite Terrane of western Mexico: Collision and subsequent rifting in a supra-subduction zone. In: Draut, A.; Clift, P.D. \& Scholl, D.W. (Eds.). Formation and Applications of the Sedimentary Record in Arc Collision Zones. Geological Society of America Special Paper, 436: 279-308. http://dx.doi. org/10.1130/2008.2436(13)

Corona-Chávez, P. (1988). Análisis estratigráfico-estructural de la porción centro-oriental de la Sierra de Guanajuato. Instituto Politécnico Nacional, Escuela Superior de Ingeniería y Arquitectura, México, D.F. Tesis licenciatura, 60 p.

Chiodi, M.; Monod, O.; Busnardo, R.; Gaspar, D.; Sánchez, A. \& Yta, M. (1988). Une discordance ante Albienne datée par une faune d'ámmonites et de braquiopodes de type Téthysien au Mexique Central. Geobios, 21: 125-135. http://dx.doi.org/10.1016/ S0016-6995(88)80014-7 
Dávila-Alcocer, V.M. \& Martínez-Reyes, J. (1987). Una edad cretácica para las rocas basales de la Sierra de Guanajuato. In: Simposio sobre la geología de la Sierra de Guanajuato: Resúmenes. UNAM, Instituto de Geología, 19-20.

Dürr, S.B. (1994). Quick estimation of pebble volumes. Journal of Sedimentary Research, 64 (3a): 677-679. http://dx.doi.org/10.1306/D4267E56-2B26-11 D7-8648000102C1865D

Echegoyén-Sánchez, J.; Romero-Martínez, S. \& Velázquez-Silva, S. (1970). Geología y yacimientos minerales de la parte central del distrito minero de Guanajuato. Boletín (Consejo de Recursos Minerales no Renovables), 75: 1-35.

Edwards, J.D. (1955). Studies of some early Tertiary red conglomerates of central Mexico. U.S. Geological Survey, Profesional Paper, 264-H: 153-185.

Escalona-Alcázar, F.D.J.; Solari, L.; García y Barragán, J.C.; Carrillo-Castillo, C.; Bluhm-Gutiérrez, J.; García-Sandoval, P.; Nieto-Samaniego, A.F. \& NúñezPeña, E. P. (2016). The Palaeocene-early Oligocene Zacatecas conglomerate, Mexico: sedimentology, detrital zircon $\mathrm{U}-\mathrm{Pb}$ ages, and sandstone provenance. International Geology Review, 58(7): 826-848. http:// dx.doi.org/10.1080/00206814.2015.1125809

Ferrusquia-Villafranca, I. (1987). Reubicación geocronológica del Conglomerado Guanajuato basada en nuevos mamíferos. In: Programa, resúmenes y guía de excursión del simposio sobre la geología de la región de la sierra de Guanajuato, Guanajuato, 28-30 de abril. UNAM, Instituto de Geología, México, 21-23.

Freydier, C.; Martinez, R.J.; Lapierre, H.; Tardy, M. \& Coulon, C. (1996). The Early Cretaceous Arperos oceanic basin (western Mexico). Geochemical evidence for an a seismic ridge formed near a spreading center. Tectonophysics, 259 (4): 343-367. http://dx. doi.org/10.1016/0040-1951(95)00143-3

Freydier, C.; Lapierre, H.; Ruiz, J.; Tardy, M.; Martínez, R. \& Coulon, C. (2000). The Early Cretaceous Arperos basin: An oceanic domain dividing the Guerrero arc from nuclear Mexico evidenced by the geochemistry of the lavas and sediments. Journal of South American Earth Sciences, 13 (4-5): 325-336. http://dx.doi.org/10.1016/ S0895-9811(00)00027-4

Fries, C.; Hibbard, C.W. \& Dunkle, D.H. (1955). Early Cenozoic vertebrates in the Red conglomerate al Guanajuato, Mexico. Smithsonian Miscellaneous Collection, 123(7), $25 \mathrm{p}$.

Gross, W.H. (1975). New ore discovery and source of silver-gold veins, Guanajuato, Mexico. Economic Geology, 70(7): 1175-1189. http://dx.doi.org/10.2113/ gsecongeo.70.7.1175

Guiza, R. (1949). Estudio geológico del distrito minero de Guanajuato. Boletín (Instituto Nacional para la investigación Recursos Minerales), 22, 75 p.
Labarthe-Hernández, G.; Tristán-González, M. \& Aranda-Gómez, J.J. (1982). Revisión estratigráfica del Cenozoico de la parte central del Estado de San Luis Potosí. Instituto de Geología y Metalurgia de la Universidad de San Luis Potosí, México, Folleto Técnico $\mathrm{n}^{\circ} 85,208 \mathrm{p}$.

Lapierre, H.; Ortiz, E.; Abouchami, W.; Monod, O.; Coulon, C. \& Zimmermann, J.L. (1992). A crustal section of an intra-oceanic island arc; the Late Jurassic-Early Cretaceous Guanajuato magmatic sequence, central Mexico. Earth and Planetary Science Letters, 108 (1-3): 61-77. http://dx.doi. org/10.1016/0012-821X(92)90060-9

Martínez-Reyes, J. (1992). Mapa geológico de la Sierra de Guanajuato, E 1:100,000, con resumen de la geología de la Sierra de Guanajuato. UNAM, Instituto de Geología. Cartas geológicas y mineras, 8 .

Martini, M.; Mori, L.; Solari, L. \& Centeno-García, E. (2011). Sandstone provenance of the Arperos Basin (Sierra de Guanajuato, central Mexico): Late Jurassic-Early Cretaceous back-arc spreading as the foundation of the Guerrero terrane. The Journal of Geology, 119(6): 597-617. http://dx.doi. org/10.1086/661989

Martini, M.; Solari, L. \& Camprubí, A. (2013). Kinematics of the Guerrero terrane accretion in the Sierra de Guanajuato, central Mexico: new insights for the structural evolution of arc-continent collisional zones. International Geology Review, 55(5): 574-589. http:// dx.doi.org/10.1080/00206814.2012.729361

Miall, A. (1996). The geology of fluvial deposits. Sedimentary Facies, Basin Analysis and Petroleum Geology. Springer-Verlag. 482 p. http://dx.doi. org/10.1007/978-3-662-03237-4

Mills, H.H. (1979). Downstream rounding of pebbles-a quantitative review. Journal of Sedimentary Petrology, 49(1):295-302.http://dx.doi.org/10.1306/212F77202B24-11D7-8648000102C1865D

Monod, O.; Lapierre, H.; Chiodi, M.; Martínez-Reyes, J.; Calvet, P.; Ortíz-Hernández, L.E. \& Zimmermann, J.L. (1990). Reconstitution d 'un arc insulaire intra-oceanique au Mexique central- la sequence volcano-plutonique de Guanajuato (Cretace inferieur). Comptes rendus des Seances de l'Academie des Sciences de Paris, serie 2, 310: 45-51.

Nemec, W. \& Muszynski, A. (1982). Volcaniclastic alluvial aprons in the Tertiary of Sofia district (Bulgaria). Annales Societatis Geologorum Poloniae, 52 (1-4): 239-303.

Nieto-Samaniego, Á.F.; Báez-López, J.A.; Levresse, G.; Alaniz-Álvarez, S.A.; Ortega-Obregón, C.; LópezMartínez, M. \& Solé-Viñas, J. (2016). New stratigraphic, geochronological, and structural data from the southern Guanajuato Mining District, México: implications for the caldera hypothesis. International Geology Review, 58(2): 246-262. http://dx.doi.org/1 $0.1080 / 00206814.2015 .1072745$ 
Nieto Samaniego, A.F. (1992). Fallamiento y estratigrafía cenozoicos en la parte sudoriental de la Sierra de Guanajuato. Revista Mexicana de Ciencias Geológicas, 9(2): 146-155.

Nieto-Samaniego, A.F.; Macías-Romo, C. \& Alaniz-Álvarez, S.A. (1996). Nuevas edades isotópicas de la cubierta volcánica cenozoica de la parte meridional de la Mesa Central, México. Revista Mexicana de Ciencias Geológicas, 13(1): 117-122.

Nieto-Samaniego, A.F.; Alaniz Álvarez, S.A. \& Camprubi Cano, A. (2005). La Mesa Central de México: estratigrafía, estructura y evolución tectónica cenozoica. Boletín de la Sociedad Geológica Mexicana, 3: 285-317.

Omaña, L., Miranda-Avilés, R. \& Puy-Alquiza, M.J., (2015). Berriasian-early Valanginian calcareous shallow-water facies from the Arperos Basin: A proposal from the foraminiferal assemblage of the clasts of the Guanajuato Conglomerate, central Mexico. Boletín de la Sociedad Geológica Mexicana, 67 (1): 45-57.

Ortiz-Hernández, L.E.; Chiodi, M.; Lapierre, H.; Monod, O. \& Calvet, Ph. (1992). El arco intraoceánico alóctono (Cretácico Inferior) de Guanajuato-Características petrográficas, geoquímicas, estructurales e isotópicas del complejo filoniano y de las lavas basálticas asociadas; implicaciones geodinámicas. Revista mexicana de ciencias geológicas, 9(2): 125-145.

Ortiz-Hernández, L.E. \& Martínez-Reyes, J. (1993). Geological structure, petrological and geochemical constraints for the centralmost segment of the Guerrero Terrane (Sierra de Guanajuato, central Mexico): Guidebook of field trip C. First Circum-Pacific and Circum-Atlantic Terrane Conference, Guanajuato (México), November 5-22, 25 p.
Ortiz-Hernandez, E.L.; Acevedo-Sandoval, O.A. \& Flores-Castro, K.; (2003). Early Cretaceous intraplate seamounts from Guanajuato, central México, geochemical and mineralogical data. Revista Mexicana de Ciencias Geológicas, 20(1): 27-40.

Puy-Alquiza, M.J.; Miranda-Aviles, R.; Cruz-Cruz, M.; Pérez-Arbizu, O.; Vega-González, M. \& Ana-Zanor, G. (2014). Geochemistry and depositional environment of the Losero Formation in the Mesa Central, México. Boletín de la Sociedad Geológica Mexicana, 66(3): 413-430.

Quintero-Legorreta, O. (1992). Geología de la región de Comanja, estados de Guanajuato y Jalisco. Revista Mexicana de Ciencias Geológicas, 10(1): 6-25.

Randall-Roberts, J.A.; Saldaña, A.E. \& Clark, K.F. (1994). Exploration in a volcano-plutonic center at Guanajuato, Mexico. Economic Geology, 89 (8): 17221751. http://dx.doi.org/10.2113/gsecongeo.89.8.1722

Rust, B.R. (1972). Pebble orientation in fluvial sediments. Journal of Sedimentary Petrology, 42(2): 384-388. http://dx.doi.org/10.1306/74D7255E-2B21-11D78648000102C1865D

Stein, G.; Lapierre, H.; Monod, O.; Zimmermann, J.L. \& Vidal, R. (1993). Petrology of some Mexican Mesozoic plutons-sources and tectonic environments. Journal of South American Earth Sciences, 7(1): 1-7. http://dx.doi.org/10.1016/0895-9811(94)90029-9

Tardy, M.; Lapierre, H.; Boudier, J-L.; Yta, M. \& Coulon, Ch. (1991). The Late Jurassic-Eearly Cretaceous arc of western Mexico (Guerrero terrane); origin and geodynamic evolution. Convención sobre la evolución geológica de México y I Congreso mexicano de Mineralogía, Memoria: 213-215.

Wandke, A. \& Martínez, J. (1928). The Guanajuato mining district, Guanajuato, Mexico. Economic Geology, 23 (1): 1-44. http://dx.doi.org/10.2113/gsecongeo.23.1.1 